\title{
Mutation of p53 and consecutive selective drug resistance in B-CLL occurs as a consequence of prior DNA-damaging chemotherapy
}

\author{
I Sturm ${ }^{1,4}$, AG Bosanquet ${ }^{2,3,4}$, S Hermann ${ }^{1}$, D Güner ${ }^{1}$, B Dörken ${ }^{1}$ \\ and PT Daniek ${ }^{\star, 1}$ \\ 1 Department of Hematology, Oncology and Tumor Immunology, Charité- \\ Campus Berlin-Buch, Humboldt University, 13125 Berlin-Buch, Germany \\ 2 Bath Cancer Research, Royal United Hospital, Bath BA1 3NG, UK \\ ${ }^{3}$ Department of Medical Sciences, University of Bath, Bath BA2 7AY, UK \\ 4 The authors IS and $A B$ contributed equally to this work \\ * Corresponding author: P T Daniel, Department of Hematology, Oncology and \\ Tumor Immunology, Charité-Campus Berlin-Buch, Humboldt University, \\ Lindenberger Weg 80, 13125 Berlin-Buch, Germany. Tel./Fax: +49 309417 \\ 1644; E-mail: pdaniel@mdc-berlin.de
}

Received 22.7.02; revised 11.10.02; accepted 16.10 .02 Edited by G Melino

\begin{abstract}
Inactivation of p53 has been shown to correlate with poor prognosis and drug resistance in malignant tumors. Nevertheless, few reports have directly shown such effects in primary tumor cells. Here, we investigated the p53 mutational status in 138 B-CLL samples and compared these findings with drug and $\gamma$-irradiation sensitivity profiles. p53 mutations resulted not only in a shorter survival but, notably also in selective resistance to alkylating agents, fludarabine and $\gamma$ irradiation. In contrast, no such effect was observed for vincristine, anthracyclines and glucocorticoids. Thus, these latter compounds induce cell death at least in part by p53independent pathways. Interestingly, p53 mutations clustered in patients who had received prior chemotherapy. In fact, we show for the first time that treatment with DNA-damaging alkylating agents correlates with occurrence of p53 mutations in a clinical setting. This finding may explain at least to some extent the development of resistance to second-line anticancer chemotherapy.

Cell Death and Differentiation (2003) 10, 477-484. doi:10.1038/ sj.cdd. 4401194
\end{abstract}

Keywords: p53 mutation; alkylating drugs; apoptosis; drug sensitivity; B-CLL

Abbreviations: $\mathrm{BH}, \mathrm{Bcl}-2$ homology domain; ALL, acute lymphoblastic leukemia; CLL, chronic lymphocytic leukemia; SSCPPCR, single-stranded conformational polymorphism-polymerase chain reaction

\section{Introduction}

Chronic lymphocytic leukemia (CLL) is caused by the accumulation of small, nondividing clonal cells. While T-CLL is rare, the majority of patients present with B-lineage CLL. The growth fraction is very low in most cases and this led to the hypothesis that B-CLL is caused not only by deregulated proliferation control but also by inactivation of the apoptosis machinery leading to accumulation of the malignant cells. Thus, B-CLL is considered a prototypic disease of apoptosis deficiency. This may be the underlying cause for the wellaccepted fact that the disease is so far incurable by conventional cytotoxic therapies.

We and others have shown in various models that cytotoxic drugs kill via the induction of apoptosis. ${ }^{1-4}$ In fact, resistance to apoptosis results in resistance to therapy. ${ }^{5}$ Nevertheless, up to now, amazingly little effort has been made to connect specific defects in the apoptosis signalling cascade with resistance or sensitivity to specific cytotoxic drugs in cancer patients.

In addition to the intrinsic resistance to apoptosis in CLL, the further disruption of apoptotic pathways may lead to the development of resistance to therapy. For B-CLL patients, it has been shown that the inactivation of the central apoptosis regulator p53, a key regulator of cell death upon DNA damage, ${ }^{6}$ is a parameter associated with a poor prognosis. ${ }^{7,8}$ Disruption of p53 may occur either by mutation or as a consequence of deletion of the chromosomal region on chromosome 17p coding for the p53 gene. In addition, such events have been linked to drug resistance in B-CLL. ${ }^{8,9}$ Approximately, $10 \%$ of B-CLL patients carry p53 mutations as a the exons 5-8, that is, the DNA-binding domain, while p53 inactivation in acute lymphatic leukemias is a rather rare event. $^{10}$ Loss of p53 function may result in the deficient activation of p53 target genes (reviewed in Daniel et al. ${ }^{11}$ and Daniel $^{12}$ ) and death effectors such as Bax, ${ }^{13-17}$ the BH3-only proteins Noxa or Puma ${ }^{18-20}$ and APAF-1. ${ }^{21,22}$ Most functional data on the consequences of p53 inactivation in relation to drug sensitivity were, however, generated in cell line models. ${ }^{23}$ Furthermore, the majority of p53 analyses in clinical tumor samples shows effects on patient survival, but do not provide direct and hard evidence for drug resistance.

In addition, little is known, especially in B-CLL, about the classes of chemotherapeutic drugs that depend on an intact p53 for their cytotoxic action. We therefore analyzed a series of 138 B-CLL samples for mutation in the DNA-binding domain of the p53 gene and determined drug sensitivity profiles across a broad spectrum of commonly employed cytotoxic B-CLL therapies.

As expected, we observed a shorter survival in patients with B-CLL carrying p53 gene mutations. More interestingly, however, we report for the first time that the frequency of 
Table 1 Patient characteristics

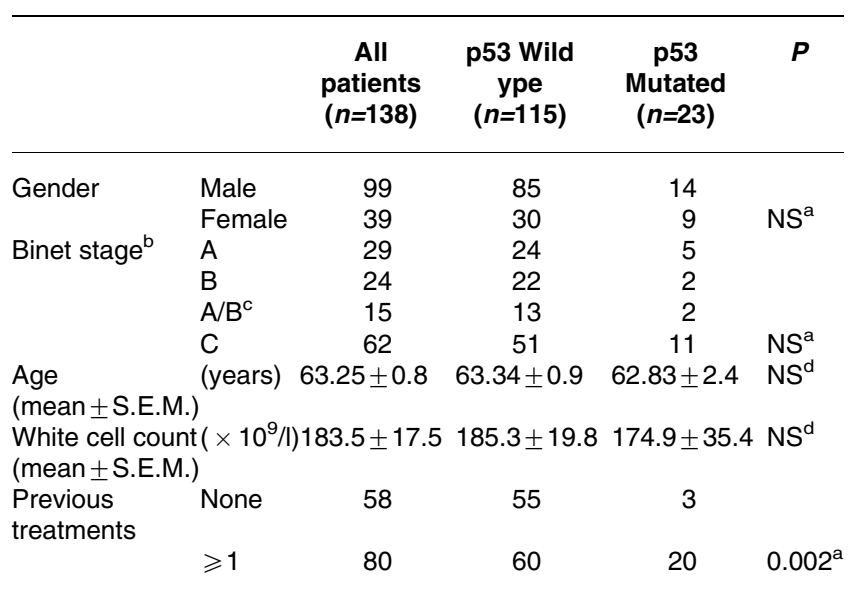

${ }^{a} \chi^{2}$-Test. ${ }^{b}$ Data available for 130 patients. ${ }^{c}$ In 15 cases, the assignment to stage $A$ or $B$ was not possible. This group is referred to as stage A/B. ${ }^{d} t$-test. NS: not significant

p53 mutations is significantly increased in patients who had received prior chemotherapy with alkylating agents. To our knowledge, this is the first report showing p53 mutation and/or selection of p53 mutant clones upon DNA-damaging therapy in a clinical setting in patients. Thus, such DNA-damaging therapies might be linked to inactivation of key genes such as p53 in the malignant cells and the consecutive development of resistance to therapy. In addition, we demonstrate that p53mutated CLL cells display selective but not overall drug resistance, that is, that p53-inactivated cells are more resistant to the alkylating agents, fludarabine, irradiation, but not to steroids, doxorubicin or vincristine.

\section{Results}

\section{Patients and specimens}

We examined 138 B-CLL specimens of patients treated at different hospitals in the UK with treatment regimen according to the physician's discretion. In total, 99 specimens were from male patients, 39 from females. Patient characteristics are shown in Table 1. Of the 80 patients that were previously treated, 62 had received an alkylating agent (either chlorambucil or cyclophosphamide). The cohort of patients was typical of those encountered in routine clinics.

\section{Ex vivo drug sensitivity}

Drug sensitivity was assessed by the ex vivo apoptotic differential staining assay. ${ }^{24}$ The chemotherapeutic drugs tested in all 138 samples were fludarabine, chlorambucil and doxorubicin. Only subsets of patient samples were tested with methylprednisolone $(n=137)$, cyclophosphamide (as mafosfamide in vitro) $(n=133)$, the vinca alkaloid vincristine $(n=104)$ and ionizing radiation ( $2 \mathrm{~Gy}$ by a ${ }^{137} \mathrm{Cs}$ source) $(n=83)$. All treatment methods induced apoptosis in a dose-dependent manner. As previously reported, individual patient drug sensitivity profiles showed a broad range of drug sensitivity patterns, ${ }^{25}$ reflecting the patient heterogeneity seen in the clinic.

\section{p53 mutational analysis}

By the use of genomic single-stranded conformational polymorphism-polymerase chain reaction (SSCP-PCR) analysis (Figure 1a), we found 23 of the 138 samples $(16.7 \%)$ to bear alterations in the DNA-binding domain of p53 (exons 58). This percentage is in line with previous investigations, which, although different methodologies were applied, found p53 gene mutations in classical B-CLL in $10^{26}$ to $15 \%,{ }^{27,28}$ or a dysfunctional p53 (as assessed by the inability to upregulate the transcriptionally dependent p21 after radiation) in $23.3 \% .^{29}$ Finally, in B-prolymphocytic leukemia, p53 mutations were seen in up to $53 \% .^{30}$ p53 inactivation by chromosomal deletion leading to loss of heterozygosity was observed in $12 \%$ and appears to be frequently associated with inactivation of the second allele by mutation. ${ }^{7}$ Alterations of the p53 gene are known to be associated with poor prognosis and shorter survival in B-CLL. ${ }^{7,8}$ In the present study, we confirm this finding.

To determine the sensitivity of our SSCP-PCR screening assay to detect sequence alterations, we performed spiking experiments in which we detected at least $10 \%$ mutant DNA (Figure 1b). DNA sequencing of the 23 samples with aberrant PCR products as identified by SSCP-PCR revealed point mutations in 11 cases, insertions or deletions in six cases, one silent base exchange and five intronic changes. Thus, the specificity of the SSCP-PCR procedure was $100 \%$. The

a
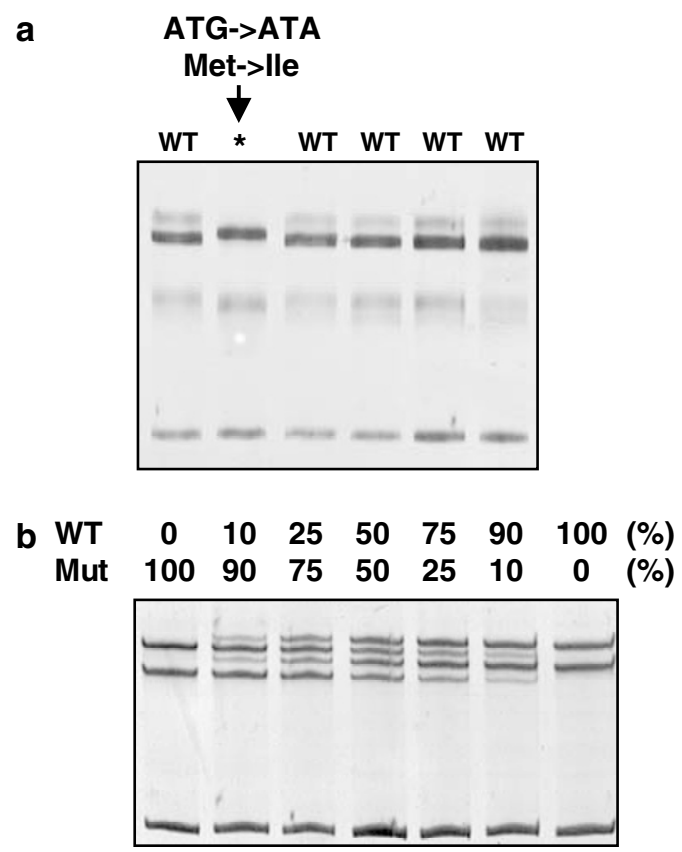

Figure 1 SSCP-PCR for p53 mutation. (a) Detection of a point mutation (ATG>ATA, pos. 711, Genbank accession number X02469) resulting in aminoacid exchange (Met>lle) (Sample \#90). (b) Spiking experiment of p53 mutant DNA (SK Mel13 melanoma cells; Codon 248 CGG>TGG, Arg>Trp) in p53 wildtype DNA (Lovo cells) 
Table 2 p53 Gene alterations as detected by SSCP and sequencing ${ }^{\mathrm{a}}$

\begin{aligned} \hline Sample No. & Sequence alteration \\ \hline 3 & GTG>GAG, Val>Glu, pos. 590+GGA \\ & >AGA Gly>Arg, pos. 595 (X02469) \\ 4 & CAT>TAT, His>Tyr, pos. 535 (X02469) \\ 6 & Ins C, pos. 902 > Stop at pos. 913 (X02469) \\ 17 & G>C at pos. 14124 (Intron 7) (U94788) \\ 33 & G>C at pos. 14124 (Intron 7) (U94788) \\ 40 & CCT>GCT, Pro>Ala, pos. 568 (X02469) \\ 45 & 49 bp deletion exon 7: pos. 14098-pos. \\ & 14147 (U94788) \\ 46 & Ins TGGAA at pos. 869 (X02469) \\ 52 & TGT>TTT, Cys>Phe, pos. 713 (X02469) \\ 54 & CGG>CCG, Arg>Pro, pos. 845 (X02469) \\ 63 & Ins A at pos. 807 > Stop at pos. 811 (X02469) \\ 76 & CGA>TGA, Arg>Stop, pos. 637 (X02469) \\ 90 & ATG>ATA, Met>lle, pos. 711 (X02469) \\ 103 & GTG>GCG, Val>Ala, pos. 606 (X02469) \\ 106 & CGC>CAC, Arg>His, pos. 524 (X02469) \\ 114 & CGG>TGG, Arg>Trp, pos.742 (X02469) \\ 117 & T>A at pos. 13456 (Intron 6) (U94788) \\ 121 & CGG>TGG, Arg>Trp, pos.742 (X02469) \\ 126 & del A at pos. 450>Stop at pos. 505 (X02469) \\ 129 & G>C at 14124 (Intron 7) (U94788) \\ 130 & G>C at 14124 (Intron 7) (U94788) \\ 138 & ATG>ATA, Met>lle, pos. 711 (X02469) \\ 150 & TTG>CTG, Leu>Leu, pos. 601 \\ & (no base exchange) (X02469) \\ & \end{aligned}

${ }^{a}$ p53 Gene reference sequence: U94788, cDNA reference sequence: X02469 (http://www.ncbi.nlm.nih.gov)

identified p53 gene alterations are listed in Table 2. The intronic base exchanges did not have any impact on drug sensitivities (see below and Table 4) and therefore could also represent polymorphisms, especially in the case of the $\mathrm{G}>\mathrm{C}$ exchange at position 14124 (intron 7) detected in four samples.

\section{Association of p53 alterations with survival and clinicopathological data}

Median overall survival, as estimated with the Kaplan-Meier method, was 31.5 months. In total, $36(26 \%)$ of the patients were censored as alive, the median follow-up of the censored patients was 62.4 months (range 39.6-98.7). In all, 29 patients were in Binet $A$ stage, with a median survival of 63.2 months, 24 patients were Binet $B$, with a median survival of 48.5 months, and 62 patients were Binet $C$, showing a median survival of 20.5 months. In 15 cases, the assignment to stage A or B was not possible, this group is referred to as stage $A / B$.

The 23 patients with p53 alterations showed a significantly shorter survival and all had died at the time of analysis (median survival 12.5 months, compared with 38.3 months in the wild-type group $(P<0.0001$, Figure 2a). Interestingly, mutations resulting in changes in the peptide sequence (point mutations, insertions or deletions) exerted the same effect on survival, as did intronic gene alterations or silent coding sequence mutations (Figure $2 \mathrm{~b}$ ). These silent mutations/
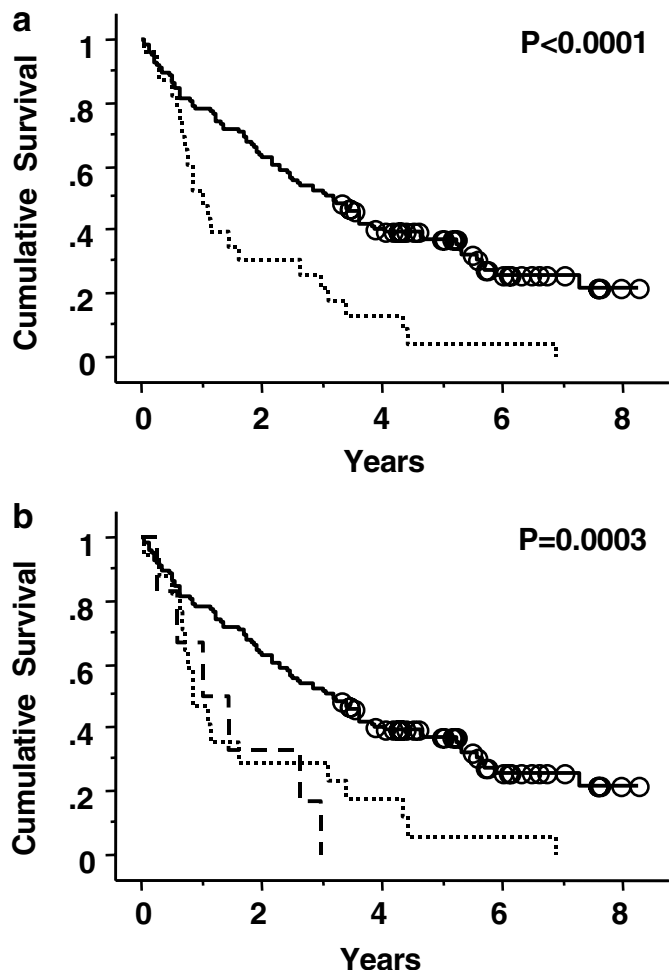

Figure 2 Impact of p53 mutation on disease prognosis. (a) Overall survival in the p53 wild-type group as compared with the group carrying p53 gene alterations (Kaplan-Meier survival estimates). Continuous line: p53 wild type ( $n=115)$; dashed line, p53 mutation ( $n=23)$. Open circles: censored patients. (b) As (a), but separated according to the type of p53 gene alteration: Continuous line: $p 53$ wild type $(n=115)$; dotted line: point mutations and insertions/deletions ( $n=17)$, dashed line: intronic point mutations $(n=5)$ and one silent point mutation $(n=1)$. Open circles: censored patients

polymorphisms were, however, not correlated with an impaired drug response. This indicates that the association between silent p53 mutation and poor survival represents an epiphenomenon.

No correlation of p53 mutational status with Binet stage or leukocyte count, age or gender could be found (Table 1). Alteration of the p53 gene was found in all Binet disease stages and was associated with a shorter overall survival in all stages (data not shown). This indicates that p53 mutation is independent from the clinical stage of the disease and the natural course of the disease. This is supported by the multivariate survival analysis (Table 3), where advanced stage (Binet $C$ versus Binet $A$ and $B$ ) and p53 mutations were independent variables for prediction of survival. The relative risk for early death was elevated 2.2-fold for patients with Binet $C$ stage $(P=0.0002)$ and 2.5 -fold for patients with p53-mutated B-CLL $(P=0.0003)$. In contrast and as expected, pretreatment status and white blood count were identified as significant prognostic factors in the univariate analysis, but were eliminated as dependent variables upon forward/backward variable selection in the multivariate analysis.

To our surprise, there was a marked correlation between the p53 status and the treatment status. Compared with 
Table 3 Univariate and multivariate survival analysis

\begin{tabular}{|c|c|c|c|}
\hline & Univariate & & \\
\hline Variable & $\begin{array}{l}\text { Relative } \\
\text { risk }\end{array}$ & $\begin{array}{c}95 \% \text { Confidence } \\
\text { interval }\end{array}$ & $P_{\text {univariate }}$ \\
\hline Stage: Binet C & 2.2 & $1.5-3.4$ & 0.0001 \\
\hline WBC high & 1.6 & $1.1-2.4$ & 0.014 \\
\hline Sex: male & 1.1 & $0.7-1.7$ & 0.7 \\
\hline Pretreatment: yes & 2.0 & $1.3-3.0$ & 0.0009 \\
\hline \multirow[t]{2}{*}{ p53 Mutation } & 2.5 & $1.6-4.1$ & 0.0001 \\
\hline & \multicolumn{3}{|c|}{ Multivariate } \\
\hline Variable & $\begin{array}{l}\text { Relative } \\
\text { risk }\end{array}$ & $\begin{array}{l}\text { 95\% Confidence } \\
\text { interval }\end{array}$ & $P_{\text {multivariate }}$ \\
\hline Stage: Binet $\mathrm{C}$ & 2.2 & $1.4-3.3$ & 0.0002 \\
\hline p53 Mutation & 2.5 & $1.5-4.2$ & 0.0003 \\
\hline
\end{tabular}

Cox Proportional Hazard Model. Variable selection for multivariate analysis was performed by both forward and backward stepwise covariate selection. WBC: white blood count (cut-off point was chosen at the median)

untreated patients, patients pretreated with chemotherapy had a significantly higher chance of bearing a p53 gene alteration: only three of the 58 chemo-naive patients had a p53 mutation, whereas 20 of 80 patients who had received prior chemotherapy for their disease showed p53 mutations ( $P=0.0022$, Table 4a). In 62 cases, pretreatment regimens included alkylating agents, that is, chlorambucil and cyclophosphamide. Of these samples 18 were found to bear a p53 gene alteration, whereas only four samples in the group of 60 'alkylating-agent naive' patients had p53 gene mutations. In 16 cases, specification of preatreatment was not available, of these patients only one sample had a p53 gene alteration (Table 4b, $P=0.0017$ ). Regarding the type of mutation, especially point mutations were associated with the pretreatment by use of alkylating agents as expected from the mode of action of chlorambucil and cyclophosphamide.

Table 4 (a) p53 Mutation and pretreatment status ${ }^{a}$

\begin{tabular}{|c|c|c|c|c|}
\hline & Pretreatment & \multicolumn{3}{|c|}{$\begin{array}{c}\text { No } \\
\text { pretreatment }\end{array}$} \\
\hline \multirow{4}{*}{$\begin{array}{l}\text { p53 Mutation } \\
\text { p53 Wild type } \\
\text { (b) p53 Mutat }\end{array}$} & 20 & & $\begin{array}{r}3 \\
55\end{array}$ & \\
\hline & 60 & & 55 & \\
\hline & $\begin{array}{l}\text { ion and specif } \\
\text { Pretreatment }\end{array}$ & ied pretreat & tment status & \\
\hline & $\begin{array}{c}\text { Alkylating } \\
\text { agent }\end{array}$ & $\begin{array}{l}\text { Without } \\
\text { alkylating } \\
\text { agents }\end{array}$ & $\begin{array}{l}\text { Unknown } \\
\text { regime }\end{array}$ & $\begin{array}{c}\text { No } \\
\text { pretreatment }\end{array}$ \\
\hline p53 Mutation & 18 & 1 & 1 & 3 \\
\hline p53 Wild type & 44 & 1 & 15 & 55 \\
\hline
\end{tabular}

${ }^{\mathrm{a} C}$ Contingency table, Fisher's exact test: $P=0.0022, \chi^{2}$ test: $P=0.001 .{ }^{\mathrm{b} C o n t i n-}$ gency table, $\chi^{2}$ Test: $P=0.0017$

\section{Correlation of p53 alterations with in vitro drug sensitivity}

To establish if inactivation of p53 is related to resistance to chemotherapy, we compared the $\mathrm{LC}_{90}$ values for a panel of relevant drugs currently employed in CLL therapy in relation to the p53 genotype. This analysis shows that silent mutations, while associated with a worse prognosis and shorter overall survival, do not coincide with resistance to anticancer drugs or irradiation. In contrast, the $\mathrm{LC}_{90}$ for chlorambucil and fludarabine was significantly higher in the p53-mutated subgroup as compared with the p53 wild-type samples (Table 5). Similarly, B-CLL cells carrying a p53 mutation showed a significantly impaired induction of apoptosis upon $\gamma$-irradiation with a fixed dose of $2 \mathrm{~Gy}$ (Table 5). For mafosfamide, there was only a trend towards resistance, which just missed statistical significance. In contrast, the p53 status did not have an impact on drug sensitivities for steroids (prednisolone not shown) and vincristine, as well as for doxorubicin, suggesting that these drugs may activate p53-independent death programs to exert their cytotoxic activities in the B-CLL cells.

\section{Discussion}

The p53/Bax pathway is a frequent target for inactivation, for example, by mutation, in a variety of tumors. $6,16,17,31,32$ Loss of p53 function results in an impaired response to DNAdamaging therapies, that is, apoptosis induced by anticancer drugs or irradiation. ${ }^{33-36}$ We previously observed that the loss of $\mathrm{Bax}$ is related to chemoresistance in B-CLL. ${ }^{13}$ In the present work, we therefore addressed the role of inactivation of p53, an upstream transcriptional activator of the Bax and other apoptosis promoting genes. To this end, we performed a mutational analysis of the p53 DNA-binding domain (exons 58) and compared these data with the drug sensitivity profiles of 138 patients with B-CLL. We demonstrate that p53 inactivation is associated with selective resistance to irradiation, alkylating agents, fludarabine and irradiation but not with resistance to anthracyclines, vincristine and glucocorticoids. Thus, inactivation of p53 results in resistance to some but not all anticancer drugs.

The key finding of our study is, however, that the occurrence of p53 gene alterations is strongly associated with prior chemotherapy for CLL. To our knowledge, our present study is the first report to demonstrate that chemotherapy treatment of B-CLL patients is related to the occurrence of p53 mutations and the development of selective drug resistance. A close association was seen between pretreatment with alkylating agents and mutation of $\mathrm{p} 53$. This does not, however, rule out that p53 mutation is solely related to therapy with alkylating agents and similar effects might arise from other DNA-damaging therapies. Our findings suggest therefore that DNA-damaging anticancer treatment is potentially causative for the development of p53 inactivation and the resulting resistance to therapy. Thus, alkylating therapies may select for resistant CLL clones resistant not only to the initially employed alkylating compounds but also result in resistance to fludarabine. This finding is novel and has not been described previously. Possible explanations are 
Table 5 Type of p53 mutation and resistance to anticancer drugs

\begin{tabular}{|c|c|c|c|c|c|}
\hline & WT & Mutation & $P$ & Intron or silent & $\boldsymbol{P}$ \\
\hline$\gamma$-Irradiation (\% surviving cells) & $29.6 \pm 3.5(n=69)$ & $60.6 \pm 11.5(n=9)$ & 0.0075 & $34.5 \pm 11.2(n=5)$ & 0.58 \\
\hline $\log _{10} L_{90}$ chlorambucil & $0.61 \pm 0.06(n=115)$ & $1.17 \pm 0.11(n=17)$ & 0.0003 & $0.81 \pm 0.22(n=6)$ & 0.38 \\
\hline $\log _{10} L C_{90}$ mafosfamide & $0.27 \pm 0.04(n=111)$ & $0.45 \pm 0.09(n=16)$ & 0.095 & $0.41 \pm 0.13(n=6)$ & 0.41 \\
\hline $\log _{10}$ LC $_{90}$ fludarabine & $0.06 \pm 0.07(n=115)$ & $0.44 \pm 0.19(n=17)$ & 0.037 & $0.00 \pm 0.27(n=6)$ & 0.79 \\
\hline $\log _{10} L_{90}$ vincristine & $-0.15 \pm 0.08(n=83)$ & $-0.11 \pm 0.17(n=17)$ & 0.76 & $-0.14 \pm 0.37(n=4)$ & 0.84 \\
\hline $\log _{10} L^{L} C_{90}$ doxorubicin & $-0.58 \pm 0.03(n=115)$ & $-0.52 \pm 0.09(n=17)$ & 0.60 & $-0.58 \pm 0.16(n=6)$ & 0.97 \\
\hline $\log _{10} L_{90}$ methylprednisolone & $1.02 \pm 0.11(n=114)$ & $1.01 \pm 0.31(n=17)$ & 0.98 & $0.88 \pm 0.40(n=6)$ & 0.76 \\
\hline
\end{tabular}

Comparison of $\log _{10} L^{L} C_{90}$ concentrations (for the cytotoxic drugs) or percentage of surviving cells (for the irradiated cells after a fixed $\gamma$-irradiation with 2 Gy) for chlorambucil, mafosfamide, fludarabine, $\gamma$-irradiation, vincristine, doxorubicin or methylprednisolone. Mean \pm S.E.M. is given. Statistical significance was calculated by means of the two-sided Mann-Whitney $U$-test. WT: p53 wild type, mutation: p53 mutation with amino acid exchange, intron or silent: no amino acid exchange

that most studies have been performed with smaller patient numbers, with a consequently low statistical power or that this rather obvious question was simply not asked.

In a similar line, several studies reported an increased incidence of secondary acute leukemias after treatment of BCLL with chlorambucil. ${ }^{37-39}$ Thus, pretreatment seems to induce genetic damage which may result in secondary acute leukemia. Such genotoxic events may also be the underlying pathogenetic mechanism of the $\mathrm{p} 53$ mutations we observed in B-CLL secondary to alkylating agent treatment.

Another possible explanation is that p53 mutations accumulate during 'normal' progression to higher clinical stages. Nevertheless, in this cohort no correlation was found between p53 mutational state and disease stage, leukocyte count or patient age. This makes the last point rather unlikely and supports the interpretation that there may be a causative link between DNA-damaging therapy, consecutive p53 inactivation and selection for a resistant genotype. This point is also supported by the observation that alkylating agents may induce p53 inactivation by mutation in experimental tumor models both in vitro and in vivo. ${ }^{40-42}$

Another possibility for the significant association of prior alkylating chemotherapy and p53 mutation could be that patients with p53-mutated B-CLL are more likely to receive treatment than do patients without p53 mutations. This is, however, not very likely as an underlying cause since we observed the stringent correlation of p53 mutation with prior chemotherapy only in the case of alkylating agents and not for other therapeutic modalities. Furthermore, we observed the occurrence of p53 mutations upon alkylating chemotherapy in all disease stages from early Binet $A$ to more advanced Binet $B$ and $C$ stages. There was no significant correlation between disease stage and the presence of p53 mutations. In the same vein, a multivariate analysis showed that Binet stage and p53 mutation are independent prognostic indicators.

In addition, an increased rate of p53 gene mutations was reported in samples from relapsed ALL patients. ${ }^{43,44}$ Notably, we were not able to show such an association of increased p53 mutation in relapsed ALL as compared with primary childhood ALL in another large cohort. ${ }^{10}$ Another possibility, apart from a direct mutagenic effect on the p53 gene, is the selection of pre-existing subclones with a mutated p53 that would not occur to this extent in the absence of genotoxic damage. Such mutation and selection phenomena have been described previously in cell line and animal models. ${ }^{45}$
Genotoxic damage, for example by environmental or endogenous DNA-damaging agents, could lead to p53 mutation and such clones might then be selected under the pressure of anticancer chemotherapy.

Furthermore, intronic base exchanges and silent point mutations in the p53 gene resulted in the same reduced overall survival as compared with those patients whose samples bear mutations resulting in amino-acid exchange or a frameshift. This indicates that the association between silent p53 mutation and poor survival may represent an epiphenomen, especially since these silent mutations are not correlated with an impaired drug response. The silent p53 mutations could therefore be associated with upstream defects, for example, in DNA repair, as underlying cause for the poor prognosis and apparent genetic instability in these patients. Significantly, the fact that there is a close association with prior chemotherapies but no impact on drug-induced apoptosis argues against selection as an underlying cause for these silent p53 mutations.

A surprising finding of our study is the differential impact of p53 mutation on the sensitivities to different cytotoxic drugs. In detail, we observed a correlation of p53 mutation with increased resistance to chlorambucil, fludarabine and irradiation. A trend in the same direction was observed for mafosfamide. Nevertheless, no significant association of drug sensitivity was found for vincristine, doxorubicin and methylprednisolone. For anthracyclines, we previously found a correlation for the expression levels of Bax. ${ }^{2,4,13}$ This suggests that these drugs exert at least part of their cytotoxic activities by other signalling pathways, thereby possibly circumventing the requirement of a proficient $\mathrm{p} 53$.

Some light has been shed on the mechanisms of fludarabine-induced apoptosis in B-CLL and the necessity of an intact p53 gene for fludarabine-induced cell death. Nevertheless, the available data are ambiguous: some authors find a strong correlation of $p 53$ gene inactivation with fludarabine resistance in vivo, ${ }^{7}$ whereas others found only a weak association, ${ }^{46}$ or no association with fludarabine response at all, ${ }^{47}$ but rather with chlorambucil response, ${ }^{48}$ or with multidrug resistance. ${ }^{9}$ Therefore, additional genetic defects may contribute to fludarabine resistance. This is in line with previous data on nucleoside analogues which showed that these nucleoside analogues may directly activate the downstream apoptosis cascade, possibly by direct activation of APAF $-1,{ }^{49,50}$ a transcriptional target of $p 53 .^{21,22}$ 
It is obvious from these data that different drugs and ionizing irradiation depend to a different extent on an intact p53. Nevertheless, the molecular basis of the differential impact of p53 mutation on drug sensitivities is still unclear. In a previous study, we have studied the impact of Bax on chemosensitivity of B-CLL. ${ }^{13}$ Loss of Bax correlated with resistance to anthracyclines, alkylating agents and vincristine. In contrast, nucleoside analogues and glucocorticoids showed induction of cell death even in Bax-deficient CLL cells. Furthermore, Bax levels were only slightly decreased in p53-mutated CLL cells. Thus, differential expression of Bax does not appear to be the cause of the differential drug sensitivity of p53 wild-type versus mutated CLL cells.

Finally, we provide a rational basis for selection of active compounds for the treatment of p53-mutated B-CLL. While alkalyting agents, nucleoside analogues and irradiation appear to depend at least to some extent on wild-type p53, other therapeutics do not and are capable of circumventing p53 genetic defects. Similar findings have been obtained for paclitaxel (taxol), which is successfully employed in advanced solid tumors and has been shown previously to circumvent p53 deficiency to induce apoptotic death ${ }^{51,52}$. Therefore, p53 mutation is currently investigated in ongoing clinical trials in BCLL to establish the usefulness of p53 genotyping in clinical routine.

\section{Materials and Methods}

\section{Patients}

Peripheral blood from $138 \mathrm{~B}-\mathrm{CLL}$ patients was analyzed for drug sensitivity to a panel of B-CLL drugs and radiation using fresh cells. The same samples were analyzed for mutations in the p53 DNA-binding domain, using snap-frozen cells from the same specimens. Clinicopathological data of the 138 patients are given in Table 1. Of the 138 patients, 80 were pretreated $(58 \%)$ with one to six drug regimens (mean number of pretreatments for these 80 patients \pm S.E.M.: $1.93 \pm 1.005$ ). Pretreated patients were a minimum of 7 days postchemotherapy when blood was drawn for assay. Patients were staged according to Binet's classification and diagnosis of B-CLL was confirmed according to the $\mathrm{NCl}$ guidelines ${ }^{53}$ by morphology, a white cell count of $>15 \times 10^{9}$ cells/l and cell markers including coexpression of CD5 and B-cell markers (CD19, CD20, and CD23) on leukemic cells.

\section{Chemosensitivity assay}

Drug-induced cell death was determined by the use of a morphometric test. In brief, peripheral blood lymphocytes were obtained using density gradient centrifugation over HistoPaque 1077 (Sigma, Poole, UK). Cells from the interface were aspirated, washed twice in medium made up with RPMI 1640 supplemented with gentamycin $(80 \mu \mathrm{g} / \mathrm{ml})$ and L-glutamine $(2 \mathrm{mM})$ and counted by the use of a hemocytometer. Median viability for specimens was $95 \%$ (interquartile range $92-97 \%$ ), as determined by trypan blue dye exclusion. For DNA extraction, aliquots of lymphocytes $\left(10^{8}\right)$ were pelleted and snap-frozen in liquid nitrogen. For drug sensitivity testing, fresh cells $\left(8 \times 10^{4}\right)$ were incubated in duplicate in $0.6 \mathrm{ml}$ polypropylene tubes in supplemented RPMI medium or UltraCulture (BioWhittaker, Walkersville, MD, USA). Final volume of $90 \mu$ included $10 \%$ phosphate-buffered saline (PBS) either without (control samples) or with added cytotoxic drug. All classes of chemotherapy routinely used in B-CLL were tested: alkylating agents (chlorambucil and cyclophosphamide - as mafosfamide in vitro); the purine nucleoside analogue fludarabine phosphate; the corticosteroid methylprednisolone; the anthracycline doxorubicin; and the vinca alkaloid vincristine.

Cells were incubated at $37^{\circ} \mathrm{C}$ in a humidified atmosphere containing $5 \%$ $\mathrm{CO}_{2}$ for $92 \mathrm{~h}$, allowing time for all drugs studied to exert their apoptotic effect. ${ }^{54}$ In culture, B-CLL cells remain in G0/G1 phase nonproliferative state and begin to die by apoptosis over time, and for all drugs tested yield measurable drug-induced apoptosis within $92 \mathrm{~h}$. A mixture of fast green and nigrosin dyes in $10 \mu \mathrm{lPBS}$, including fixed duck erythrocytes (50 000) as an internal standard, was added to the cell suspensions to stain dead cells black before cytocentrifugation onto microscope slides. The slides were air-dried and counter-stained with Romanowsky stain. Subsequent morphological evaluation of slides by light microscopy facilitated the determination of drug efficacy at each concentration; to obtain the net effect of drug-induced apoptosis, live lymphocytes in the drug-treated samples were determined as a percentage of live lymphocytes in control cultures as described. ${ }^{54}$

\section{Mutation analysis of p53}

DNA was extracted and mutations in the $p 53$ exons 5-8 were analyzed by genomic SSCP-PCR analysis as described. ${ }^{15-17}$ DNA was stored in $10 \mathrm{mM}$ Tris $\mathrm{HCl} / 0.1 \mathrm{mM}$ EDTA buffer ( $\mathrm{pH}$ 8.7). For the PCR reaction, we used $2 \%$ of the genomic DNA (from $10^{6}$ cells) in $2 \mu \mathrm{l} ; 0.5 \mu$ l of each sense and antisense primer ( $50 \mathrm{pmol})$. Primer sequences were as follows: exon 5a: CCA GTT GCT TTA TCT GTT CA and TGT GGA ATC AAC CCA CAG; exon 5b: CAA CTG GCC AAG ACC TGC and AAC CAG CCC TGT CGT CTC T; exon 6: CTC TGA TTC CTC ACT GAT TGC and GAG ACC CCA GTT GCA AAC CA; exon 7: TTG CCA CAG GTC TCC CCA A and AGG GTG GCA AGT GGC TCC; exon 8: CCT TAC TGC CTC TTG CTT C and CGC TTC TTG TCC TGC TTG C $-0.4 \mu$ of dNTP $(12.5 \mathrm{mmol}$ of each dNTP in a total volume of $50 \mu \mathrm{l}) ; 1.5 \mu \mathrm{l} \mathrm{MgCl}_{2}(50 \mathrm{~mm})$ in reaction buffer $\left.\left(\mathrm{NH}_{4}\right)_{2} \mathrm{SO}_{4}\right)(16 \mathrm{mM})$ and $1.5 \mathrm{U}$ of Taq polymerase (InViTAQ, InViTek, Berlin, Germany). The reaction buffer, the dNTPs, the primer, $\mathrm{MgCl}_{2}$, the genomic DNA and the polymerase were mixed in water up to a total volume of $50 \mu \mathrm{l}$. The amplification was performed by the use of a thermocycler 9700 (Perkin-EImer/Cetus, Weiterstadt, Germany) according to the following protocol: exon $5 \mathrm{a}: 94^{\circ} \mathrm{C}$ for $5 \mathrm{~min}$ followed by 35 cycles at $94^{\circ} \mathrm{C}$ for $30 \mathrm{~s}, 55^{\circ} \mathrm{C}$ for $20 \mathrm{~s}, 72^{\circ} \mathrm{C}$ for $15 \mathrm{~s}$; exon $5 \mathrm{~b}$ : $94^{\circ} \mathrm{C}$ for $5 \mathrm{~min}$ followed by 35 cycles at $94^{\circ} \mathrm{C}$ for $30 \mathrm{~s}, 65^{\circ} \mathrm{C}$ for $20 \mathrm{~s}, 72^{\circ} \mathrm{C}$ for $15 \mathrm{~s}$; exon 6 : $94^{\circ} \mathrm{C}$ for $5 \mathrm{~min}$ followed by 35 cycles at $94^{\circ} \mathrm{C}$ for $30 \mathrm{~s}, 60^{\circ} \mathrm{C}$ for $20 \mathrm{~s}, 72^{\circ} \mathrm{C}$ for $15 \mathrm{~s}$; exon $7: 94^{\circ} \mathrm{C}$ for $5 \mathrm{~min}$ followed by 35 cycles at $94^{\circ} \mathrm{C}$ for $30 \mathrm{~s}$, $58^{\circ} \mathrm{C}$ for $20 \mathrm{~s}, 72^{\circ} \mathrm{C}$ for $20 \mathrm{~s}$; exon $8: 94^{\circ} \mathrm{C}$ for $5 \mathrm{~min}$ followed by 35 cycles at $94^{\circ} \mathrm{C}$ for $30 \mathrm{~s}, 60^{\circ} \mathrm{C}$ for $20 \mathrm{~s}, 72^{\circ} \mathrm{C}$ for $15 \mathrm{~s}$; final extension time of $7 \mathrm{~min}$ at $72^{\circ} \mathrm{C}$. For SSCP analysis, the amplified DNA was diluted 1:1 in DNA loading buffer ( $82 \%$ formamide, $10 \mathrm{mmol} / \mathrm{l} \mathrm{NaOH}, 50 \mathrm{mmol} / / \mathrm{EDTA}$, bromophenol blue, xylene xyanole dye). The samples were denatured at $95^{\circ} \mathrm{C}$ (5 min), chilled on ice (4 min), loaded on a $10 \%$ nondenaturing polyacrylamide gel and finally electrophoresed at $500 \mathrm{~V}$ and $50 \mathrm{~mA}$ at $10^{\circ} \mathrm{C}$ in a Multiphor electrophoresis chamber (Pharmacia, Freiburg, Germany). Visualization was performed by silver staining.

Samples with aberrant bands were sequenced, either the PCR product or the aberrant band was cut out of the dried SSCP-gel, reamplified and sequenced. Primers for sequencing analysis were the primers used for SSCP analysis. Sequencing was performed with the ABI Prism ${ }^{T M}$ BigDye $^{\mathrm{TM}}$ Terminator Cycle Sequencing Ready Reaction Kit (PE Applied Biosystems, Weiterstadt) according to the manufacturer's recommendation. Sequencing was performed with an $\mathrm{ABI}$ Prism 310 sequencer Sequence analysis was done with the software Sequencher ${ }^{\mathrm{TM}} 3.0$ (Gene 
Codes Corporation, Ann Arbor, MI, USA). Sequence aberrations were confirmed in an independent sequencing reaction.

\section{Data analysis}

Logistic curves were fitted to the cell count survival data; the logit of survival probability was taken to be linear with respect to the logarithm of drug concentration. ${ }^{25} \mathrm{LC}_{90}$ doses, that is, the concentration of drug to produce a $90 \%$ reduction in cell survival compared with control cells, were determined by calculating the log dose at which the fitted survival probability was equal to 0.1 . As $\mathrm{LC}_{90}$ results are log normal, all $\mathrm{LC}_{90}$ values were logged (base 10) before calculation of mean, S.E.M. and statistical tests. For intervariable assessment, the $t$-test (parametric test) or the Mann-Whitney U-test (nonparametric test) and the $\chi^{2}$-test or Fisher's exact test - where appropriate - were applied. Overall survival was estimated by the Kaplan-Meier product-limit method, starting from the time of sample collection. The survival curves were compared by the means of the Logrank-Mantel-Cox-test. For multivariate survival analysis, a Cox Proportional Hazard Model was employed. Variable selection for multivariate analysis was done by both forward and backward stepwise covariate selection.

\section{Acknowledgments}

We thank Jana Rossius, David Head, Alison Burlton and Philip Bell for expert technical assistance. The following drug companies kindly supplied drugs: Asta (mafosfamide), Schering (fludarabine). This work was funded in part by the following grants: 'Schwerpunktprogramm Apoptose' by the Deutsche Krebshilfe and by the network grant 'Regulation of apoptosis in tissue homeostasis and cancer' by the European Union 'Training and Mobility of Researchers' program.

\section{References}

1. Radetzki S, Kohne $\mathrm{CH}$, von Haefen $\mathrm{C}$, Gillissen B, Sturm I, Dörken B and Daniel PT (2002) The apoptosis promoting bcl-2 homologues bak and nbk/bik overcome drug resistance in $\mathrm{mdr}-1$-negative and $\mathrm{mdr}-1$-overexpressing breast cancer cell lines. Oncogene 21: 227-238

2. Hemmati PG, Gillissen B, von Haefen C, Wendt J, Stärck L, Güner D, Dörken B and Daniel PT (2002) Adenovirus-mediated overexpression of $p 14^{\mathrm{ARF}}$ induces p53 and bax-independent apoptosis. Oncogene 21: 3149-3161

3. Friedrich K, Wieder T, von Haefen C, Radetzki S, Schulze-Osthoff K, Jänicke R, Dörken B and Daniel PT (2001) Overexpression of caspase-3 restores sensitivity for drug-induced apoptosis in breast cancer cells with acquired drug resistance. Oncogene 20: 2749-2460

4. von Haefen C, Wieder T, Gillissen B, Stärck L, Graupner V, Dörken B and Daniel PT (2002) Ceramide induces mitochondrial activation and apoptosis via a bax-dependent pathway in human carcinoma cells. Oncogene 21: 40094019

5. Wu GS and El-Deiry WS (1996) Apoptotic death of tumor cells correlates with chemosensitivity, independent of p53 or bcl-2. Clin. Cancer Res. 2: 623-633

6. May P and May E (1999) Twenty years of p53 research: structural and functional aspects of the p53 protein. Oncogene 18: 7621-7636

7. Döhner H, Fischer K, Bentz M, Hansen K, Benner A, Cabot G, Diehl D, Schlenk R, Coy J and Stilgenbauer S (1995) P53 gene deletion predicts for poor survival and non-response to therapy with purine analogs in chronic B-cell leukemias. Blood 85: 1580-1589

8. Wattel E, Preudhomme C, Hecquet B, Vanrumbeke M, Quesnel B, Dervite I, Morel $P$ and Fenaux P (1994) P53 mutations are associated with resistance to chemotherapy and short survival in hematologic malignancies. Blood 84: 3148-3157
9. Silber R, Degar B, Costin D, Newcomb EW, Mani M, Rosenberg CR, Morse L, Drygas JC, Canellakis ZN and Potmesil M (1994) Chemosensitivity of lymphocytes from patients with B-cell chronic lymphocytic leukemia to chlorambucil, fludarabine, and camptothecin analogs. Blood 84: 3440-3446

10. Prokop A, Wieder T, Sturm I, Essmann F, Seeger K, Wuchter C, Ludwig WD, Henze G, Dörken B and Daniel PT (2000) Relapse in childhood acute lymphoblastic leukemia is associated with a decrease of the bax/bcl-2 ratio and loss of spontaneous caspase-3 processing in vivo. Leukemia 14: 1606-1613

11. Daniel PT, Sturm I, Wieder T and Schulze-Osthoff $K$ (2001) The kiss of death: promises and failures of death receptors and ligands in cancer therapy. Leukemia 15: 1022-1032

12. Daniel PT (2000) Dissecting the pathways to death. Leukemia 14: 2035-2044

13. Bosanquet AG, Sturm I, Wieder T, Essmann F, Bosanquet MI, Head DJ, Dörken B and Daniel PT (2002) Bax expression correlates with cellular drug sensitivity to doxorubicin, cyclophosphamide and chlorambucil but not fludarabine, cladribine or corticosteroids in B cell chronic lymphocytic leukemia. Leukemia 16: 1035-1044

14. Schelwies K, Sturm I, Grabowski $P$, Scherbl H, Süchindler I, Hermann S, Stein H, Buhr HJ, Riecken EO, Zeitz M, Dörken B and Daniel PT (2002) Analysis of p53/bax in primary colorectal carcinoma: low bax protein expression is a negative prognostic factor in UICC stage III tumors. Int. J. Cancer 99: 589-596

15. Sturm I, Kohne CH, Wolff G, Petrowsky H, Hillebrand T, Hauptmann S, Lorenz M, Dörken B and Daniel PT (1999) Analysis of the p53/bax pathway in colorectal cancer: low bax is a negative prognostic factor in patients with resected liver metastases. J. Clin. Oncol. 17: 1364-1374

16. Sturm I, Papadopoulos S, Hillebrand T, Benter T, Luck HJ, Wolff G, Dörken B and Daniel PT (2000) Impaired bax protein expression in breast cancer: mutational analysis of the bax and the p53 gene. Int. J. Cancer 87: 517-521

17. Sturm I, Petrowsky H, Volz R, Lorenz M, Radetzki S, Hillebrand T, Wolff G, Hauptmann S, Dörken B and Daniel PT (2001) Analysis of p53/bax/p16 ink4al cdkn2 in esophageal squamous cell carcinoma: high bax and $p 16^{\text {ink4a/cdkn2 }}$ identifies patients with good prognosis. J. Clin. Oncol. 19: 2272-2281

18. Puthalakath $\mathrm{H}$ and Strasser $\mathrm{A}$ (2002) Keeping killers on a tight leash: transcriptional and post-translational control of the pro-apoptotic activity of BH3-only proteins. Cell Death Differ. 9: 505-512

19. Oda E, Ohki R, Murasawa H, Nemoto J, Shibue T, Yamashita T, Tokino T, Taniguchi T and Tanaka N (2000) Noxa, a BH3-only member of the bcl-2 family and candidate mediator of p53-induced apoptosis. Science 288: 1053-1058

20. Nakano K and Vousden KH (2001) Puma, a novel proapoptotic gene, is induced by p53. Mol. Cell 7: 683-694

21. Kannan K, Kaminski N, Rechavi G, Jakob-Hirsch J, Amariglio N and Givol D (2001) DNA microarray analysis of genes involved in p53 mediated apoptosis: activation of APAF-1. Oncogene 20: 3449-3455

22. Moroni MC, Hickman ES, Denchi EL, Caprara G, Colli E, Cecconi F, Muller H and Helin K (2001) APAF-1 is a transcriptional target for E2F and p53. Nat. Cell Biol. 3: 552-558

23. Lowe SW, Ruley HE, Jacks T and Housman DE (1993) P53-dependent apoptosis modulates the cytotoxicity of anticancer agents. Cell 74: 957-967

24. Bosanquet AG and Bell PB (1996) Novel ex vivo analysis of nonclassical, pleiotropic drug resistance and collateral sensitivity induced by therapy provides a rationale for treatment strategies in chronic lymphocytic leukemia. Blood 87: 1962-1971

25. Bosanquet $A G$ and Bosanquet $\mathrm{Ml}$ (2000) Ex vivo assessment of drug response by differential staining cytotoxicity (disc) assay suggests a biological basis for equality of chemotherapy irrespective of age for patients with chronic lymphocytic leukaemia. Leukemia 14: 712-715

26. Fenaux P, Preudhomme C, Lai JL, Quiquandon I, Jonveaux P, Vanrumbeke M, Sartiaux C, Morel P, Loucheux-Lefebvre MH and Bauters F (1992) Mutations of the $p 53$ gene in b-cell chronic lymphocytic leukemia: a report on 39 cases with cytogenetic analysis. Leukemia 6: 246-250

27. Gaidano G, Ballerini P, Gong JZ, Inghirami G, Neri A, Newcomb EW, Magrath IT, Knowles DM and Dalla-Favera R (1991) P53 mutations in human lymphoid malignancies: association with Burkitt lymphoma and chronic lymphocytic leukemia. Proc. Natl. Acad. Sci. USA 88: 5413-5417

28. el Rouby S, Thomas A, Costin D, Rosenberg CR, Potmesil M, Silber R and Newcomb EW (1993) P53 gene mutation in B-cell chronic lymphocytic leukemia is associated with drug resistance and is independent of $\mathrm{mdr} 1 / \mathrm{mdr} 3$ gene expression. Blood 82: 3452-3459 
29. Pettitt AR, Sherrington PD and Cawley JC (2000) Role of poly(ADPribosyl)ation in the killing of chronic lymphocytic leukemia cells by purine analogues. Cancer Res. 60: 4187-4193

30. Lens D, De Schouwer PJ, Hamoudi RA, Abdul-Rauf M, Farahat N, Matutes E, Crook T, Dyer MJ and Catovsky D (1997) P53 abnormalities in B-cell prolymphocytic leukemia. Blood 89: 2015-2023

31. Mrozek A, Petrowsky H, Sturm I, Krauss J, Hermann S, Hauptmann S, Lorenz $\mathrm{M}$ and Daniel $\mathrm{P}$ (2003) Combined p53/bax mutation results in extremely poor prognosis in gastric carcinoma with low microsatellite instability. Cell Death Differ. 10: 461-467

32. Güner D, Sturm I, Hemmati PG, Hermann S, Hauptmann S, Wurm R, Budach V, Dörken B, Lorenz M and Daniel PT (2002) Multigene analysis of Rb-pathway and apoptosis-control in esophageal squamous cell carcinoma identifies patients with good prognosis. Int. J. Cancer 103: 445-454

33. El-Deiry WS (2001) Insights into cancer therapeutic design based on p53 and trail receptor signaling. Cell Death Differ. 8: 1066-1075

34. Benchimol S (2001) P53-dependent pathways of apoptosis. Cell Death Differ. 8: $1049-1051$

35. Wang JY (2001) DNA damage and apoptosis. Cell Death Differ. 8: 1047-1048

36. Chow BM, Li YQ and Wong CS (2000) Radiation-induced apoptosis in the adult central nervous system is p53-dependent. Cell Death Differ. 7: 712-720

37. Dighiero G, Maloum K, Desablens B, Cazin B, Navarro M, Leblay R, Leporrier M, Jaubert J, Lepeu G, Dreyfus B, Binet JL and Travade P (1998) Chlorambucil in indolent chronic lymphocytic leukemia. French cooperative group on chronic lymphocytic leukemia. N. Engl. J. Med. 338: 1506-1514

38. Grunwald HW and Rosner F (1998) Secondary acute leukemia in chronic lymphocytic leukemia. N. Engl. J. Med. 339: 924

39. Zarrabi MH, Grunwald HW and Rosner F (1977) Chronic lymphocytic leukemia terminating in acute leukemia. Arch. Intern. Med. 137: 1059-1054

40. Brathwaite O, Bayona W and Newcomb EW (1992) P53 mutations in C57BI/6J murine thymic lymphomas induced by gamma-irradiation and $n$ methylnitrosourea. Cancer Res. 52: 3791-3795

41. Tweddle DA, Malcolm AJ, Bown N, Pearson AD and Lunec J (2001) Evidence for the development of p53 mutations after cytotoxic therapy in a neuroblastoma cell line. Cancer Res. 61: 8-13

42. Schmitt CA, Fridman JS, Yang M, Lee S, Baranov E, Hoffman RM and Lowe SW (2002) A senescence program controlled by $p 53$ and $p 16^{\text {INK4a }}$ contributes to the outcome of cancer therapy. Cell 109: 335-346

43. Diccianni MB, Yu J, Hsiao M, Mukherjee S, Shao LE and Yu AL (1994) Clinical significance of p53 mutations in relapsed T-cell acute lymphoblastic leukemia. Blood 84: 3105-3112
44. Blau O, Avigad S, Stark B, Kodman Y, Luria D, Cohen IJ and Zaizov R (1997) Exon 5 mutations in the p53 gene in relapsed childhood acute lymphoblastic leukemia. Leuk. Res. 21: 721-729

45. Le Rhun Y, Duthu A, Ehrhart JC, Michiels F, May E and May P (1994) Directional selection associated with clonal expansion of p53 mutant cells during neoplastic development of carcinogen-treated rat embryo lung epithelial cells. Oncogene 9: 263-271

46. Pettitt AR, Sherrington PD and Cawley JC (1999) The effect of p53 dysfunction on purine analogue cytotoxicity in chronic lymphocytic leukaemia. Br. J. Haematol. 106: 1049-1051

47. Thomas A, El RS, Reed JC, Krajewski S, Silber R, Potmesil M and Newcomb EW (1996) Drug-induced apoptosis in B-cell chronic lymphocytic leukemia: relationship between p53 gene mutation and bcl-2/bax proteins in drug resistance. Oncogene 12: 1055-1062

48. Morabito F, Filangeri M, Callea I, Sculli G, Callea V, Fracchiolla NS, Neri A and Brugiatelli M (1997) Bcl-2 protein expression and p53 gene mutation in chronic lymphocytic leukemia: correlation with in vitro sensitivity to chlorambucil and purine analogs. Haematologica 82: 16-20

49. Genini D, Adachi S, Chao Q, Rose DW, Carrera CJ, Cottam HB, Carson DA and Leoni LM (2000) Deoxyadenosine analogs induce programmed cell death in chronic lymphocytic leukemia cells by damaging the DNA and by directly affecting the mitochondria. Blood 96: 3537-3543

50. Leoni LM, Chao Q, Cottam HB, Genini D, Rosenbach M, Carrera CJ, Budihardjo I, Wang X and Carson DA (1998) Induction of an apoptotic program in cell-free extracts by 2-chloro-2'-deoxyadenosine $5^{\prime}$-triphosphate and cytochrome c. Proc. Natl. Acad. Sci. USA 95: 9567-9571

51. Wahl AF, Donaldson KL, Fairchild C, Lee FY, Foster SA, Demers GW and Galloway DA (1996) Loss of normal p53 function confers sensitization to taxol by increasing G2/M arrest and apoptosis. Nat. Med. 2: 72-79

52. Woods CM, Zhu J, McQueney PA, Bollag D and Lazarides E (1995) Taxolinduced mitotic block triggers rapid onset of a p53-independent apoptotic pathway. Mol. Med. 1: 506-526

53. Cheson BD, Bennett JM, Grever M, Kay N, Keating MJ, O'Brien S and Rai KR (1996) National cancer institute-sponsored working group guidelines for chronic lymphocytic leukemia: revised guidelines for diagnosis and treatment. Blood 87: 4990-4997

54. Bosanquet AG and Bell PB (1996) Enhanced ex vivo drug sensitivity testing of chronic lymphocytic leukaemia using refined disc assay methodology. Leuk. Res. 20: 143-153 